\title{
Mitigasi Bencana Pada Layanan Jasa Penyedia Akomodasi Pariwisata Pulau Nusa Lembongan Kabupaten Klungkung
}

Ayu Asri Wilasasti a,1, I Made Sukanaa, 2

1'wilasasti@gmai.com, 22made_sukana@unud.ac.id

a Program Studi S1 Destinasi Pariwisata, Fakultas Pariwisata,Universitas Udayana, Jl. Dr. R. Goris, Denpasar, Bali 80232 Indonesia

\section{Abstract}

This research is conducted in Nusa Lembongan Island, Klungkung Regency. Based on the Indonesian laws no 24 in 2007 about Disaster management, it states that the territory of the united republic of Indonesia has geographical, hydrological, and demographic conditions that are very possible in the occurience of disaster. The aimed of this research is to discover the industry of disaster mitigation on the service provider of tourism accommodation in Nusa Lembongan IslandKlungkung Regency. The data in this research is a qualitative data. the sourch of the primer and sekunder datas. Were collected through observation, interview and documentation. The determination technique of informan use is proposive procedure.

The result of this research showed that hotel, resort and bungalow accommodation has prepared themselves to facing disaster in the preparation, the service provider prepare themselves by disaster knowledge, mitigation tools and disaster sign, also mitigation practive when disaster happens. Four from five accomoation has prepared more for fire accidents meanwhile the other one is prepped more to face Tsunami.

As for suggestions that can be given to accomoation service and govermeuntis being able to set an example of what is good and reaffirm the regent is rules applied through the SK about mitigation disaster. The local communities are expected to know more about natural phenomena and to cooperate with the government to gain knowledge.The researcher hopes this resech can be sort knowledge about disaster mitigation on accommodation provider so in the future there will be more deep.

Keywords : Mitigation of disaster, Accomodation, Industry of tourism, Nusa Lembongan Island

\section{PENDAHULUAN}

Bali adalah salah satu pulau yang eksotis di Nusantara dengan perkembangan perekonomian yang bertitik tumpu pada pariwisata. Setiap Kabupaten di Pulau Bali memiliki daya tarik wisata yang unggul, baik itu budaya, alam dan buatan. Salah satu kabupaten yang kini telah menjadi tujuan wisata adalah Kabupaten Klungkung.

Kabupaten Klungkung adalah kabupaten terkecil yang ada di Bali. Kabupaten ini menjadi incaran para wisatawan karena memiliki ulau yang indah yang disebut sebagai Pulau Nusa Penida dan Pulau Nusa Lembongan. Pemerintah menghususkan kegiatan pariwisata berada di Pulau Nusa Lembongan karena kaya akan alam bawah lautnya. Hal ini menyebabkan kunjungan wisatawan meningkat setiap tahunnya.

Disisi lain, pariwisata sangat rentan dengan isu-isu kenyamanan dan keamanan sehingga perlu diantisipasi melalui pengembangan jaminan keamanan yang diawali dengan kesiap-siagaan bencana bagi penyedia jasa pariwisata di Kabupaten Klungkung.

Sesuai dengan UU Republik Indonesia Nomor 24 Tahun $2007 \quad$ Tentang
Penanggulangan Bencana menyatakan wilayah NKRI mempunyai keadaan geografi, hidrologi, dan demografi yang sangat rentan terjadi bencana/musibah yang dibuat oleh faktor alam, non alam dan faktor manusia yang berdampak terjadinya korban, rusaknya lingkungan, ruginya harta dan benda serta berdampak pada psikologis bagi masyarakat yang menjadi korban.

Potensi bahaya di Kabupaten Klungkung adalah gempa, tsunami, angin kencang, letusan gunung api, banjir kekeringan, longsor, gelombang ekstrim, abrasi serta kebakaran lahan. Sehingga penelitian yang berjudul "Mitigasi Bencana Pada Layanan Jasa Penyedia Akomodasi Pariwisata Pulau Nusa Lembongan Kabupaten Klungkung" perlu dilakukan. Tujuan dari penelitian ini adalah mengurangi resiko bencana yang terdapat di Pulau Nusa Lembongan dengan upaya Mitigasi bencana.

\section{KEPUSTAKAAN}

Tinjauan hasil penelitian sebelumnya merupakan acuan untuk digunakan sebagai perbandingan dengan penelitian yang akan dilakukan. Acuan tersebut berupa hasil dari 
penelitian sebelumnya dengan lokus maupun focus yang sama, sehingga bisa mendapat gambaran awal bahwa penelitian yang akan dilakukan memang penting untuk dilakukan. Berikut ini merupakan penelitian yang digunakan sebagai tinjauan pada penelitian ini : penelitian pertama yang dilaksanakan oleh Baharuddin tahun 2011 berjudul Zonasi Kawasan Pesisir Pantai Makassar Berbasis Mitigasi Bencana. Pada penelitian ini dijelaskan tentang mitigasi bencana dengan melihat zonasi di pantai Makasar melalui tinjauan aspek penataan ruang dalam pengelolaan area laut dan pesisir, oleh Menteri Pemukiman dan Prasana Wilayah, 2003 halaman 10-11. Penelitian ini memiliki kesamaan focus dengan penelitian yang akan dilakukan yaitu pengurangan resiko bencana engan menerapkan mitigasi.

Penelitian selanjutnya yang juga dilaksanakan oleh Erawati dan Yasa tahun 2012 dengan judul Analisis Pola Pertumbuhan Ekonomi Dan Sektor Potensial Kabupaten Klungkung. Dalam penelitian ini dilakukan untuk mengetahui tahapan pertumbuhan dari segi ekonomi yang dapat dilihat dari pendapatan per-kapita serta pertumbuhan ekonomi, dapat mengetahui sektor ekonomi yang potensial dan mengetahui peluang kerja yang diciptakan dari sektor ekonomi potensial di Kabupaten Klungkung. Penelitian ini memiliki kesamaan lokus dengan penelitian yang akan dilakukan yaitu di Kabupaten Klungkung.

Dalam artikel Mitigasi Bencana Pada Layanan Jasa Penyedia Akomodasi Pariwisata Pulau Nusa Lembongan Kabupaten Klungkung memakai beberapa konsep digunakan diantaranya:

\section{Konsep Mitigasi}

Mitigasi yaitu suatu upaya yang dipergunakan untuk meminimalisir resiko terjadinya bencana, baik itu melalui pembenahan secara fisik serta penyadaran dan meningkatkan kemampuan dalam menghadapi ancaman - ancaman bencana (UU No. 24 tahun 2007).

Dalam penelitian ini Konsep Mitigasi Bencana digunakan sebagai acuan dalam penyelenggaraan pariwisata terkait dengan upaya meminimalisir dampak akibat bencana.

\section{Konsep Bencana}

Menurut UU tentang Penanggulangan Bencana No. 24 tahun 2007 Bencana yaitu serangkaian kejadian yang mencekam serta mengganggu kehidupan masyarakat yang diakibatkan oleh faktor alam, non alam serta faktor manusia yang berdampak mengakibatkan timbulnya korban, kerusakan lingkungan, kerugian harta dan benda, dan berdampak pada psikologis. Bencana terdiri dari bencana alam, bencana nonalam, bencana sosial.

Dalam penelitian ini konsep bencana digunakan untuk mengklasifikasikan jenis bencana yang mungkin terjadi di Nusa Lembongan.

\section{METODE PENELITIAN}

Lokasi dari penelitian ini berada di Penelitian ini bertempat di Pulau Nusa Lembongan yang merupakan ikon dari pariwisata di Kabupaten Klungkung. Sedangkan batasan untuk permasalahan adalah mitigasi bencana pada layanan penyedia jasa akomodasi pariwisata di Pulau Nusa Lembongan yaitu : pengetahuan mengenai bencana undangundang no.24 tahun 2007 mengenai jenis-jenis bencana, peralatan dan rambu-rambu mitigasi dan praktik mitigas bencana pada layanan penyedia jasa akomodasi pariwisata di Pulau Nusa Lembongan.

Sumber data yang dipergunakan yaitu data primer, yang terkait mengenai meliputi kondisi saat ini di Pulau Nusa Lembongan dengan melakukan observasi, melakukan wawancara dengan penyedia jasa layanan akomodasi mengenai bencana yang sering terjadi. Teknik pengumpulan data dilakukan dengan observasike lapangan untuk surevei langsung ke lapangan untuk mendapatkan data mengenai potensi bahaya di Nusa Lembongan, wawancara mendalam dengan narasumber secara langsung untuk mendapatkan informasi yang akurat mengenai potensi bahaya yang menimpa Pulau Nusa Lembongan.

Teknik penentuan informan dipilih menggunakan metode prosedur purposive sampling. Prosedur purpisif sampling merupakan salah satu cara menentukan informan melalui pemilihan kelompok peserta sesuai dengan kriteria yang terpilih dengan masalah tertentu (Bungin, 2007). Adapun informan yang dipilih dalam penelitian ini 
diantaranya : kepala dinas BPBD, dinas pariwisata di Kabupaten Klungkung, badan pembangunan daerah, BMKG dan penyedia layanan jasa akomodasi.

Teknik analisis data dilakukan reduksi data dengan cara memilih data untuk di focuskan dan disederhanakan, kemudian data ysng sudah di dapat disusun berupa teks naratif yang merupakan gambaran peneliti. Langkah terakhir adalah pengambilan kesimpulan atau verivikasi.

\section{HASIL DAN PEMBAHASAN}

Pulau Nusa lembongan adalah salah satu destinasi yang sangat menarik perhatian wisatawan adalah Yellow Bridge atau yang biasa disebut Jembatan Kuning yang menghubungkan antara Nusa Ceningan dan Nusa Lembongan. Selain itu, daya tarik alam bahari di setiap sudutnya menjadi incaran para wisatawan. Sehingga dibutuhkan kesiapan untuk menampung wisatawan yang akan berkunjung. Salah satu yang harus dipenuhi adalah Akomodasi. Akan tetapi akomodasi yang ada di Pulau Nusa Lembongan berada di pesisir pantai yang rawan bencana. Hal ini akan menimbulkan potensi bahaya yang dapat mengganggu keamanan dan kenyamanan wisatawan. Sehingga dibutuhkan persiapan dini untuk mengatasi bencana yang akan datang.

\subsection{Mitigasi Bencana Pada Layanan} Penyedia Jasa Akomodasi Pariwisata

Pelibatan dunia usaha dalam
penanggulangan implementasi dari pasal 28 UU No. 24 tahun 2007 tentang penanggulangan bencana yang menyatakan bahwa lembaga yang bergerak di bidang usaha memperoleh kesempatan di dalam penanggulangan bencana, baik itu melalui sendiri maupun melalui bersama dengan pihak yang terkait. Keterlibatan dunia usaha kususnya penyedia jasa layanan pariwisata diharapkan mempu memenuhi standar manajemen bencana seperti Pengetahuan mengenai bencana dan peralatan yang memadai.

\subsubsection{Pengetahuan Mengenai Bencana UU No. 24 tahun 2007 Mengenai Jenis-Jenis Bencana}

1. Gempa bumi terguncangnya bumi yang disebabkan oleh terbenturnya antar lempeng tektonik, yang disebabkan gunung berapi. Berdasarkan data BMKG menyatakan bahwa gempa yang terjadi di Nusa Lembongan tergolong kategori gempa kecil yaitu kisaran2.4 hingga 3.7

2. Tsunami adalah terjadinya kenaikan gelombang air laut dengan jangka yang panjang disebabkan oleh gangguan dari dasar laut (gempa tektonik, erupsi vulkanik atau longsor).

3. Angin topan adalah putaran gerakan angin yang memiliki kecepatan $120 \mathrm{~km} / \mathrm{jam}$ atau bahkan lebih yang biasanya terjadi di daerah tropis diantara garis bali bagian utara dengan bali bagian selatan, tidak termasuk di daerah yang berdekatan dengan khatulistiwa. Angin topan biasanya diakibatkan karena bedanya tekanan di dalam sistem cuaca.

4. Angin puting beliung yaitu angin yang bertiup kencang yang datangnya mengagetkan, dimana memiliki inti, gerakannya melingkar dengan memiliki kcepatan 40-50km/jam sehingga sampai mengenai bumi dan akan menghilang dalam jangka waktu yang singkat sekitar 3 sampai dengan 5 menit.

5. Tanah longsor adalah gerakan dari massa tanah atau bebatuan yang menuruni dan keluar dari lereng karena kurangnya dari kestabilan tanah ataupun bebatuan.

6. Kekeringan yaitu ketersediaan yang jauh dibawah kebutuhan air baik itu untuk kebutuhan dalam hidup, untuk irigasi, kegiatan perekonomian serta untuk kegiatan lingkungan.

7. Letusan gunung yaitu lubang kepundan di kerak bumi tempat keluarnya magma, cairan dan gas kepermukaan. Gunung meletus diakibatkan oleh masih aktifnya gunung merapi sehingga menghasilkan erupsi.

8. Banjir yaitu bencana yang disebabkan oleh curah hujan yang terlalu tinggi atau diatas normal.

9. Gelombang pasang yaitu gelombang yang tinggi diakibatkan karena dampak terjadinya siklon tropis di wilayah Indonesia serta sangat berpotensi kuat mengakibatkan terjadinya bencana alam.

10. Abrasi yaitu tahapan pengikisan di pantai yang disebabkan gelombang air laut.

11. Kebakaran yaitu suatu kondisi yang dimana bangunan seperti rumah, pasar, 
gedung dilanda habis oleh api yang menimbulkan korban serta kerugian.

\subsubsection{Peralatan Mitigasi dan Rmbu- RAambu Bencana}

Sesuai dengan peraturan Bupati Klungkung No. 31 Tahun 2016 Tentang Pedoman Umum Kesiapsiagaan Penanggulangan Bencana Dalam Usaha Pariwisata, bahwa setiap usaha pariwisata harus memiliki peralatan untuk meminilalisir kerusakan yang terjadi. Adapun mitigasi bencana dalam usaha pariwisata terdiri dari : Mitigasi strukturan yang meliputi tersedianya denah/peta banguan yang ada di setiap sisi, terdapat area yang bisa digunakan sebagai titik kumpul saat keadaan darurat, tersedianya sarana proteksi kebakaran aktif Alat Pemadam Api Ringan (APAR) HIDRANT, Bel atau Spiker, pemeriksaan sarana proteksi berskala, staf bisa mengaplikasikan alat, tersedianya fasilitas dan aksesibilitas untuk kelompok disable. Sedangkan mitigasi non struktural adalah adanya kebijakan perusahaan peduli terhadap pengelolaan lingkungan demi keamanan dan keselamatan bila terjadi ancaman bencana dan Mengadakan pelatihan pengurangan Resiko Bencana secara berkala sesuai perkembangan peraturan perundang-undangan dan perkembangan ilmu pengetahuan.

Dari aspek yang telah dijabarkan bahwa lima Akomodasi pariwisata yang diantaranya terdiri dari Hotel, Bungalow dan Resort di Nusa Lembongan sudah memenuhi beberapa kriteria mengenai Standar Kesiapsiagaan Bencana Dalam Usaha Pariwisata yaitu peta bangunan, peralatan kebakaran, pengoprasian alat oleh semua staf, pemeriksaan secara berskala, asuransi, penangkal petir dan mengadakan pelatihan pengurangan resiko bencana secara berskala.

\subsubsection{Praktik Bencana Pada Layanan Penyedia Jasa Akomodasi Pariwisata Di Pulau Nusa Lembongan}

Adapun temuan yang diperoleh dari hasil wawancara terhadap staff atau pegawai dari lima penyedia akomodasi penginapan di Pulau Nusa Lembongan yaitu Hotel Bali Hai, D'Nusa Resort, Mahagiri Resort, Tjendana Group, Villa's \& Resort dan Abian Hunt bahwa kelima hotel ini sudah melaksanakan berbagai prosedur yang terdapat di peraturan Bupati, akan tetapi salah satu hotel dari kelima hotel ini, belum melakukan secara optimal. Akan tetapi Hotelhotel ini telah mampu menghadapi bahaya tsunami, kebakaran dan gempa bumi melalui pelatihan yang dilakukan setiap seminggu sekali dan tata bangunan yang dirancang untuk memudahkan wisatawan atau staf untuk melarikan diri bila terjadi bencana dan tersedianya kapasitas untuk titik kumpul yang aman bila terjadi bencana.

\section{PENUTUP}

\subsection{Simpulan}

Dari hasil pembahasan yang telah diuraikan diatas, maka dapat diambil kesimpulan yaitu:

Sesuai dengan UU Republik Indonesia Nomor 24 Tahun 2007 Tentang Penanggulangan Bencana menyatakan wilayah NKRI mempunyai keadaan geografi, hidrologi, dan demografi yang sangat rentan terjadi bencana/musibah yang dibuat oleh faktor alam, non alam dan faktor manusia yang berdampak terjadinya korban, rusaknya lingkungan, ruginya harta dan benda serta berdampak pada psikologis bagi masyarakat yang menjadi korban. Sehingga diperlukan mitigasi dalam menghadapi bencana yang akan datang seperti :

1. Pengetahuan Mengenai Bencana UndangUndang No. 24 tahun 2007 Mengenai JenisJenins Bencana yaitu bencana alam yang meliputi Gempa Bumi,Tsunami, Angin Topan, Angin Putting Beliung, Tanah longsor, kekeringan, Letusan gunung Api, Banjir, Gelombang pasang atau badai, Abrasi, Kebakaran.

2. Peralatan Mitigasi dan Rambu-Rambu Bencana berupa pemadam kebakaran seperti Apar, Hydrant dan lonceng sedangkan untuk rambu-rambu bencana yang dimaksud adalah arah evakuasi untuk meuju titik kumpul atau titik aman.

3. Praktik mitigasi Bencana Pada Layanan Penyedia Jasa Akomodasi Pariwisata Di Pulau Nusa Lembongan yang telah dilakukan oleh para layanan penyedia jasa akomodasi oleh Hotel Bali Hai, Mahagiri Resort, Tjendana Group Villa \& Resort, D’Nusa Resort, Abian Hunt Resort mempersiapkan diri untuk mengahadapi bencana yaitu satu diantaranya lebih menyiapkan diri untuk bencana tsunami dan empat lainnya menyiapkan diri untuk bencana kebakaran. 


\subsection{Saran}

1. Untuk penyedia Jasa Layanan Akomodasi dan Pemerintah diharapkan mampu mencotoh akomodasi yang telah berhasil menerapkan beberapa sistem mitigasi untuk perusahaan yang telah mereka miliki baik itu Hotel, Villa maupun Resort dan untuk pemerintah lebih menegaskan kembali aturan yang ditetapkan oleh Bupati Klungkung melalui SK yang telah dikeluarkan agar pelaku usaha penyedia Jasa Layanan Pariwisata tidak lalai atas aturan dan keselamatan. Serta melengkapi atau menambah segala sesuatu yang masih kurang. Baik itu dalam program kerja maupun praktek lapangan.

2. Untuk Masyarakat Lokal diharapkan lebih memahami gejala-gejala bencana yang ada disekitar dan mau bekerjasama dengan pemeintah maupun instansi lainnya untuk menambah wawasan mengenai kebencanaan.

3. Harapan penulis agar penelitian ini dapat memberikan gambaran mengenai mitigasi bencana pada layanan akomodasi sehingga nanti mampu melakukan penelitian lanjutan guna memberikan pengetahuan yang lebih dalam lagi tentang mitigasi bencana pada layanan akomodasi dengan mempertimbangkan faktor lain yang tidak tercantum di dalam penelitian ini.

\section{DAFTAR PUSTAKA}

Anonim UU No.24 tahun 2007 tentang Penanggulangan Bencana

Anonim Keputusan Menteri Dalam Negeri Nomor 131 Tahun 2003 Tentang Pedoman Penanggulangan Bencana Dan Penanganan Pengungsi Di Daerah Menteri Dalam Negeri

Badan Meteorologi, Klimatologi dan Geofisika tentang Gempa Bumi dan Tinggi Gelombang

Badan Perencanaan Pembangunan Daerah Kabupaten Klungkung Informasi mengenai peta dan pembangunan daerah

Baharudin, Koddeng. 2011. Zonasi Kawasan Pesisir Pantai Makasar Berbasis Mitigasi Bencana. Jurnal Prosiding Hasil Penelitian Fakultas Teknik. Volume 5. Hal :4-20

Bungin, Burhan.2007. Penelitian Kualitatif. Jakarta: Prenamedia Group

Dinas Kebudayaan dan Pariwisata Pemerintah Kabupaten Klungkung tentang Peta Wilayah Kabupaten Klungkung. 2017

Dinas Kebudayaan dan Pariwisata Pemerintah Kabupaten Klungkung tentang Jumlah Kunjungan wisatawan tahun 2014-2015

Erawati, Ni Komang, dan I. Yasa. Analisis Pola Pertumbuhan Ekonomi Dan Sektor Potensial
Kabupaten Klungkung. Jurnal Ekonomi dan Bisnis Universitas Udayana. Volume 1. No. 01

Haifani, Akhmad Muktaf. Manajemen Bencana Gempa Bumi.2016

Kantor Bupati Klungkung Laporan Kerja Penanggung Jawaban tentang Kasus Bencana tahun 2014-2015

Ngurah, Ida Dewa Ayu Istri.2013. Kajian Pola Adaptasi Petani Terhadap Kekeringan Di Pulau Nusa Penida, Kabupaten Klungkung, Provinsi Bali. Tesis. Ilmu Lingkungan Universitas Gadjah Mada

Nujanah, Sugiharto, R, Kuswanda, Dede, B.P, Siswanto, Adikoesoemo. 2012. Manajemen Bencana. Bandung: Alfabeta

Silalahi, Uber. 2010. Metode Penelitian Sosial. Refika Aditama,Bandung

Sumaryadi, I. Nyoman. (2010). Sosiologi pemerintah. Dari prespektif pelayanan, pemberdayaan, interaksi dan system kepemimpinan pemerintahan. Indonesia. Jakarta Ghalia Indonesia.

Sumber dari Internet :

http://id.m.wikipedia.org/wiki/Segitiga_Terumbu_Karang . Diunduh pada Sabtu, 20 Mei tahun 2017. Pukul 08.07

www.wwf.or.id/?25320/Coral-Triangle-Day-MelindungiLautan-yang-Menghubungkan-Kita-Semua. Diunduh pada Sabtu, 20 Mei tahun 2017. Pukul 08.08 